\title{
Selected advances in genetics-cream of the crop
}

\author{
Annual Review of Genetics \\ Edited by: Bonnie L Bassler, Michael Lichten and Gertrud Schüpbach \\ ISBN: 978-0-8243-1249-7 \\ Published by: Annual Reviews, 2015 \\ Price: $\$ 99.00$
}

European Journal of Human Genetics (2017) 25, 657; doi:10.1038/ejhg.2017.14

The lives of scientists can be almost as complicated as those of the organisms they study. One particular challenge relates to the old generalists versus specialists argument. The choice between the two depends on the scientist's personality and skills, and there is no right answer. Specialists may forever disapprove of the way generalists misunderstand science at the micro-level, whereas a generalist may criticize the way a specialist's work lacks adequate frame of reference, is too niche, and lacks applicability to other fields. For this reason, a series like The Annual Reviews provides a rare neutral platform where both generalists and specialists can find useful coverage of the knowledge accumulated in their fields.

First published in 1967, with contributions from eminent scholars like Richard Lewontin, the series made a long way over the past 49 years, during which it split into two, with the sister series titled: Annual Review of Genomics and Human Genetics. However, the relationship between the two series remained convoluted, which reflects on the 'generalists versus specialists' debate: should human studies be printed solely in the sister series as they are more relevant to human scholars, or in the original series? There are good arguments for both options; however, rather than taking part in this nearly two-decades-old debate, I prefer to convey my excitement over finding such a diverse set of high-quality papers of a very broad scope covering the fundamental aspects of genetics and genomics. Topics like gene therapy, nitrogen use in crop plants, DNA repair, meiotic signaling, population genetics, stress signaling, and bioinformatic tools appear alongside a comprehensive discussion in the genetic basis of language.
Most readers will not read the entire book. However, those who will browse through will find that the editors of the new Annual Review of Genetics aimed to cover all the major genetic milestones reached in 2015, though with a few notable omissions (eg, CRISPR). Readers will likely stumble upon the fascinating history of patenting genetic material as it developed from the mid-twentieth century. There, authors Sherkow and Greely explain the principles of patent law before they review the short but dense history of genetic patenting. Of special focus are the social and political reactions to recent disputes involving the Human Genome Diversity Project (HGDP), in which the senior author was personally involved, and Myriad Genetics, Inc., which serves as important lessons for follow-up endeavors. Disputes over gene patents lasted nearly 35 years, and, although the Supreme Court's decision on Myriad broke the company's monopoly on the BRCA1 and BRCA2 in the United States, it is still possible to patent DNA sequences as long as they are 'substantially different' from those that occur in nature. It is therefore reasonable to expect that genetic patents will continue being a bone of contention between those seeking to protect their work and the public that opposes patenting molecules that we all carry.

There are many more fascinating reviews in this 718-page volume, but reviewing them all is unfeasible. In summary, this book contains over 30 high-quality chapters that are potentially of interest to anyone interested in genetics as a resource of excellent articles covering a range of disciplines. Including an editorial piece that introduces the topics, explaining why they were selected and how they mark the milestones reached over the past year, would be highly beneficial to guide the reader through the complexities of our field.

\section{CONFLICT OF INTEREST}

The authors declare no conflict of interest.

Eran Elhaik

The University of Sheffield, Sheffield, UK

Dr E Elhaik,

E-mail: e.elhaik@sheffield.ac.uk 